pragMATIZES - Revista Latino Americana de Estudos em Cultura

Dossiê 


\title{
Políticas culturais nos territórios: contribuições para os processos de construção dos planos municipais de cultura ${ }^{1}$
}

\author{
Políticas culturales en los territorios: \\ contribuiciones a los procesos de construcción de planes de cultura
}

\author{
Cultural policies in the territories: contributions to the processes \\ of construction of municipal culture plans
}

\author{
Lia Calabre ${ }^{2}$
}

\section{Palavras-chave: \\ Políticas culturais \\ Política pública \\ Planos de cultura \\ Território \\ Cidadania cultural}

\section{Resumo:}

A garantia da cidadania democrática e cultural são elementos indispensáveis na busca da superação de desigualdades e do reconhecimento das diferenças reais existentes entre os sujeitos que habitam o território, em suas dimensões social, econômica e cultural. O objetivo fundamental de uma política cultural deveria ser o de garantir o direito à cultura, do qual gozam o conjunto dos cidadãos. O presente artigo vai trabalhar, com a aceleração desse processo de reconhecimento das políticas culturais como um campo das políticas públicas, mais especificamente, tendo por ponto de partida o cenário internacional, a partir dos anos 1970. O objetivo do artigo é o de refletir sobre a problemática das políticas culturais a partir da gestão pública municipal, tendo como ferramenta fundamental o plano de cultura com suas premissas, princípios e desafios. 


\section{Resumen:}

La garantia de la ciudadanía democrática y cultural son elementos indispensables en la búsqueda de superar las desigualdades y reconocer las diferencias reales existentes entre los sujetos que habitan el territorio, en sus dimensiones sociales, económicas y culturales. El objetivo fundamental de una política cultural debe ser garantizar el derecho a la cultura. El presente artículo busca recuperar un poco de la trayetoria de la construccíon de las políticas públicas de cultura, más específicamente, tomando como punto de partida el escenario internacional desde la década de 1970. El propósito del artículo es reflexionar sobre el problema de las políticas culturales desde la gestión pública municipal, teniendo como herramienta fundamental el plan cultural com sus premisas, principios y desafios.
Palabras clave:

Políticas culturales

Política pública

Planes de cultura

Territorio

Ciudadanía cultural

\section{Keywords:}

Cultural policies

Public Policy

Culture plans

Territory

Cultural citizenship

\section{Abstract:}

The guarantee of democratic and cultural citizenship are indispensable elements in the search to overcome inequalities and to recognize the real differences existing between the subjects that inhabit the territory, in their social, economic and cultural dimensions. The objective of a cultural policy should be to guarantee the right to culture. This article will work, with growing recognition of cultural policies as a field of public policies, taking as its starting point the international scenario, from de 1970s. The purpose of this article is to reflect on the problem of cultural policies from the municipal public management, having as a fundamental tool the culture plan with its premises, principles and challenges. 


\section{Políticas culturais nos territórios: contribuições para os processos de construção dos planos municipais de cultura}

\begin{abstract}
"A cada momento a totalidade existe como uma realidade concreta e está ao mesmo tempo em processo de transformação. A evolução jamais termina. O fato acabado é pura ilusão."

(Milton Santos - Da totalidade ao lugar)
\end{abstract}

Como podem ser construídas políticas públicas de cultura? Essa é a questão que guia a elaboração do presente artigo. Ao pensarmos sobre a problemática que envolve a relação entre a área da cultura e a construção de políticas públicas, verificamos que, no caso da América Latina, as discussões sobre a necessidade e importância da existência de políticas culturais se iniciaram, mais efetivamente, nos anos 1970, quando em muitos dos países da região ainda vigiam as ditaduras militares. A Colômbia (Conferência Intergovernamental sobre Políticas Culturais para a América Latina e Caribe -1978) e o México (Conferência Mundial de Políticas Culturais - Mondiacult - 1982) cumpriram um papel destacado no crescimento dessa discussão, sediando alguns dos principais encontros mundiais sobre políticas culturais fomentados pela UNESCO (que foi a responsável por inserir a cultura na pauta das políticas públicas de diversos governos naquele momento).

As discussões frutificaram ao longo dos anos 1980. No caso do Brasil tivemos a criação do Ministério da Cultura e a presença dos direitos culturais na Constituição Cidadã de 1988. Ações que foram seguidas pelo desmonte da área pública sob a orientação de políticas de viés neoliberal, nos anos 1990 - período no qual a área das políticas públicas de cultura ficou restrita, quase que exclusivamente, às ações das leis de incentivos, com o núcleo de decisão sobre a aplicação dos recursos nas mãos da iniciativa privada.

Os anos 2000 representaram para o Brasil, falando aqui do campo da cultura, tanto a construção de novos projetos, como o ressurgimento de algumas das discussões e ações gestadas ainda nos anos 1970 e 1980, só que dessa vez em um contexto democrático e participativo. A Ditadura Civil Militar, que teve fim em 1985, havia realizado muitas ações de estruturação no campo da gestão pública da cultura. A construç̧ão do Ministério da Cultura (MinC), que já se deu no período democrático, contou com pouca participação social, ainda que tenha sido uma demanda do Fórum Nacional de Secretários de Cultura. O chamamento da sociedade para a participação na construção das políticas de cultura só passa a ocorrer, efetivamente, nos anos 2000, na gestão do Ministro Gilberto Gil, sob o governo do Presidente Lula.

Os anos de 2003 a 2010 foram de intensas mudanças no campo da gestão pública de cultura. As ações e discussões não ficaram restritas aos limites da máquina pública do governo federal, várias e diferentes iniciativas de escuta e participação democrática foram construídas nos estados e municípios. Nos anos de 2011 a 2015, diversos dos projetos gestados nos oito anos anteriores foram sendo implementados e muitos dos programas continuados.

No campo da participação social, no período que vai de 2003 até 2015, foram convocados inúmeros setores da sociedade, de todas as regiões do país, para participar da construção de um efetivo campo de políticas públicas de cultura ${ }^{3}$, com projetos

3 Os processos participativos, com a utilização de várias ferramentas, foram acionados na construção de inúmeras políticas setoriais. Houve um crescimento significativo das conferências nacionais setoriais. 
de estruturação de mais largo prazo, tais como o Sistema Nacional de Cultura, o Plano Nacional de Cultura e o Conselho Nacional de Políticas Culturais, com um intenso trabalho na busca dos desdobramentos das ações nas esferas estadual e municipal do Sistema, com seus Planos e Conselhos.

Lançando um olhar mais abrangente sobre os anos 2003 - 2010 podemos, ainda, destacar algumas questões mais conceituais ou poderíamos, talvez, chamar de algumas inovações operacionais, que impactaram no processo efetivo da implementação da política cultural ${ }^{4}$. A primeira delas está na reafirmação constante de que tudo o que estava sendo implementado tinha por base a chamada tridimensionalidade da cultura ${ }^{5}$, composta pelas dimensões simbólica, cidadã e econômica, e definidas pelo MinC, como:

A dimensão simbólica é aquela do "cultivo" (na raiz da palavra cultura) das infinitas possibilidades de criação expressas nas práticas sociais, nos modos de vida e nas visões do mundo. [...] A dimensão cidadã consiste no reconhecimento do acesso à cultura como um direito, bem como da sua importância para a qualidade de vida e a autoestima de cada um. [...] Na dimensão econômica, inscreve-se o potencial da cultura como vetor de desenvolvimento. Trata-se de dar asas a uma importante fonte geradora de trabalho e renda, que tem muito a contribuir para o crescimento da economia brasileira. (MINC, 2010, p. 8)

Ainda que se possa afirmar que os objetivos propostos nas dimensões não te-

\footnotetext{
$4 \quad$ Parte dessa discussão foi apresentada no artigo intitulado Políticas Culturais e estratégias territoriais em tempos sombrios.

5 Termo que se tornou corrente na gestão dos Ministros Gilberto Gil e Juca Ferreira.
}

nham sido plenamente alcançados, estas estiveram todo o tempo presentes no campo discursivo dos documentos e das ações do MinC. O Ministério fez largo uso do "capital simbólico" (no sentido atribuído por Bourdieu) contido na ideia de tridimensionalidade, realizando ações que resultaram em efetivos avanços no campo da estruturação de políticas culturais em bases mais democráticas, participativas, abrangentes e cidadãs. Entram para a pauta de discussão da gestão pública, de uma maneira mais efetiva, as problemáticas dos direitos culturais, da cidadania cultural e da economia da cultura ${ }^{6}$.

Uma segunda concepção teórica que acompanhou a prática da gestão do MinC foi a da diversidade cultural. José Márcio Barros, nos chama a atenção para o fato de que:

\begin{abstract}
Reconhecer na diversidade cultural apenas a presença de diferenças estéticas é simplificar a questão. Há sempre, e é isso que torna a questão complexa, a tensão política e cognitiva de diferentes modelos de ordenamento e gestão. Diversidade cultural é a diversidade dos modos de instituir e gerir a relação com a realidade. (BARROS, 2009, p. 84)
\end{abstract}

Entre os compromissos assumidos pelo Brasil, como um dos países defensores e signatários da Convenção da Diversidade, estão os de "proteger e promover a diversidade das expressões culturais"; "criar condições para que as culturas floresçam e interajam livremente em benefício mútuo"; e, "encorajar o diálogo entre culturas". Tais compromissos colocam na ordem do dia uma questão fundamental: a do conhecimento das práticas culturais do país (ou da localidade) por parte dos gestores públicos

6 Essa questão já foi por mim trabalhada em dois outros artigos que tem como foco a participação social, presentes nas referências bibliográficas. 
(que não se restringe aos resultados obtidos com a coleta de dados estatísticos, por exemplo) ou, como nos falou José Márcio Barros, da necessidade de estar atentos "aos modos de gestão que se fazem presentes nos diferentes padrões culturais" (idem). Em verdade: "como considerar realizada a inclusão social se os valores, comportamentos, modos de vida, imaginários, raízes, práticas e heranças culturais, manifestações, fabulações e celebrações da maioria da população são desconhecidos das gestões?" (MOREIRA; FARIA, 2005, p. 12), questionam os pesquisadores Altair Moreira e Hamilton Faria ao tratarem das questões dos governos municipais, que teoricamente deveriam ser os detentores de um conhecimento mais aprofundado da realidade sob sua responsabilidade administrativa.

Os modelos de democratização da cultura aplicados em diversos países nas últimas décadas do século passado se mostraram inadequados para o florescimento de sociedades com níveis menos desiguais de práticas e acesso à cultura. $A$ ideia de um estado centralizado, no qual se originam um conjunto de decisões sobre a oferta cultural para todo o país, terminou por reproduzir um padrão concentrador do capital simbólico do qual historicamente eram detentores determinados segmentos sociais com maiores graus de escolarização e pertencentes às camadas médias e altas da população. O modelo centralizador francês de política cultural, originado na gestão de André Malraux, que inspirou alguns governos ao longo das décadas de 1960 e 1970, foi gradativamente sendo superado.

Na década de 1980 e mais intensamente na de 1990, alguns países, como a própria França, que por muito tempo mantiveram uma política de financiamento e gestão da cultura altamente centralizada, passaram a investir no processo de descentralização administrativa, decisória e financeira. No final da década de 1990, as vilas francesas já investiam nos territórios o dobro dos recursos que o Ministério da Cultura. Em um estudo sobre o processo de descentralização e de ampliação da governança territorial, o especialista francês Guy Saez alerta para a necessidade do desenvolvimento de novas lógicas para as políticas de cultura que extrapolem a dimensão puramente institucional. Alerta ainda para a urgência da mudança dos procedimentos e dos instrumentos de políticas públicas de maneira a nos autorizar a falar em uma nova ação pública fundada nos princípios do compartilhamento, da transversalidade e da territorialidade. (SAEZ, 2004, p. 43)

A Constituição Brasileira promulgada em 1988 garantiu uma maior autonomia aos municípios no campo da elaboração e da efetivação das políticas públicas. E, sem dúvida, ao pensarmos na construção de políticas públicas de cultura temos no município um nível de governo estratégico e privilegiado para a efetivação das ações. É no território que a cultura é praticada em toda a sua intensidade e diversidade. Como afirma Alfons Martinell:

Para além das leis e normas, nas cidades as comunidades organizam sua vida cultural da forma que for possível e se enriquecem culturalmente à medida que incorporam serviços públicos para facilitar seu acesso e fomentar a participação. Muitos desses processos são realizados de forma espontânea, às vezes com uma assunção dos serviços públicos por parte dos cidadãos, sem a participação do Estado. (SEMPERE, 2011, p. 64)

É nas cidades, nas localidades, nos territórios que os cidadãos realizam grande parte das práticas culturais cotidianas. Estas são espaços de vivência e convivência nos quais pode ser verificada uma dinâmica cultural intensa. No Brasil, o investimento municipal em cultura é muito desigual - cenário que se apresenta de maneira muito similar ao do conjunto das outras ta- 
xas de desigualdades apresentadas pelo país. Muitos municípios possuem um baixo grau de investimento, ainda que na média da soma do conjunto dos recursos, o IBGE nos informa que os governos municipais investem mais em cultura que os governos estaduais e o governo federal.

É o município que, mais efetivamente, dialoga com o cidadão em "seu território", que implementa as políticas públicas de proximidade, que responde às demandas locais. E, dentre um emaranhado complexo de políticas setoriais municipais, está a política pública municipal de cultura.

O objetivo fundamental de uma política cultural deveria ser o de garantir o direito à cultura, do qual deveriam gozar o conjunto dos cidadãos - como previsto na Constituição Federal e, ainda, em algumas das Constituições Estaduais e das Leis Orgânicas. Isso quer dizer que estamos falando de práticas e de desejos de ser e de fazer, ligados a questões de natureza material e imaterial. A política cultural deve ter em conta que as ações estão posicionadas nos campos do real e do simbólico, do consumo e da fruição, do acesso e das práticas. A maior parte das disputas e tensões entre o direito previsto, o direito concretizado e a negação dos direitos se fará mais evidente nos territórios, sob as administrações municipal e estadual.

Um município, independentemente do tamanho do seu território ou de sua população, é constituído por múltiplos outros recortes territoriais reais e simbólicos, onde as disputas por direitos se fazem mais evidentes.

Independente do processo de esvaziamento, dada a pouca atenção efetiva que vem sendo dispensada à construção do Sistema Nacional de Cultura, pelos três ministros da cultura que ocuparam a pasta no curto período de dois anos e meio do golpe que destituiu a Presidenta eleita Dilma Rousseff, assim como no governo que se seguiu, ao verificamos o índice de adesão ao SNC, pelos municípios brasileiros, constatamos que, em janeiro de 2018 , chegava a $45,8 \%$ do total de municípios e que seguiu crescendo até a avaliação de setembro de 2019 , como pode ser observado nas tabelas abaixo ${ }^{7}$.

\begin{tabular}{|ll|l|l|l|}
\hline & $\begin{array}{l}\text { Estados com } \\
\text { adesão }\end{array}$ & $\begin{array}{l}\text { Municípios com } \\
\text { adesão }\end{array}$ & Total de Municípios & $\begin{array}{l}\text { \% Municípios com } \\
\text { adesão }\end{array}$ \\
\hline Centro-Oeste & 4 & 199 & 467 & $42,6 \%$ \\
\hline Norte & 6 & 190 & 450 & $42,2 \%$ \\
\hline Nordeste & 9 & 888 & 1794 & $49,5 \%$ \\
\hline Sudeste & 4 & 676 & 1668 & $40,5 \%$ \\
\hline Sul & 3 & 600 & 1191 & $50,4 \%$ \\
\hline Total & 26 & 2553 & 5570 & $45,8 \%$ \\
\hline
\end{tabular}

Fonte: Sistema Nacional de Cultura - Acordo de Cooperação Federativa - atualizado em 24/01/2018 - MinC

7 É importante destacar que o presente artigo foi redigido em outubro de 2019, em um governo que extinguiu o Ministério da Cultura, transformando-o em uma Secretaria Especial da Cultura subordinada ao Ministério da Cidadania. 


\begin{tabular}{|l|l|l|l|l|}
\hline & $\begin{array}{l}\text { Estados e DF com } \\
\text { adesão }\end{array}$ & $\begin{array}{l}\text { Municípios com } \\
\text { adesão }\end{array}$ & $\begin{array}{l}\text { Total de } \\
\text { Municipios }\end{array}$ & $\begin{array}{l}\text { \% Municípios com } \\
\text { adesão }\end{array}$ \\
\hline Centro-Oeste & 4 & $209(+10)$ & 467 & $44,8 \%$ \\
\hline Norte & 7 & $191(+1)$ & 450 & $42,4 \%$ \\
\hline Nordeste & 9 & $929(+41)$ & 1794 & $51,8 \%$ \\
\hline Sudeste & 4 & $703(+27)$ & 1668 & $42,1 \%$ \\
\hline Sul & 3 & $631(+31)$ & 1191 & $53 \%$ \\
\hline Total & 27 & 2.663 & 5570 & $47,8 \%$ \\
\hline
\end{tabular}

Fonte: Sistema Nacional de Cultura - Acordo de Cooperação Federativa - atualizado em 30/09/2019 - MinC ${ }^{8}$

O quadro acima nos revela um cenário de razoável articulação interna do poder público municipal na direção da construção de políticas públicas de cultura. É importante ressaltar que para aderir ao Sistema Nacional de Cultura, o município se compromete a cumprir um conjunto de exigências, tais como a realização de conferências municipais de cultura, a elaboração de um plano municipal de cultura, a criação de um conselho de política cultural, enfim, todo um conjunto de ações que requer um diálogo intenso do poder público com a sociedade civil.

\section{Algumas reflexões indispensáveis para a construção de um plano municipal de cultura}

A garantia da cidadania democrática e cultural é elemento indispensável na busca da superação de desigualdades e do reconhecimento das diferenças reais existentes entre os sujeitos que habitam o território, em suas dimensões social, econômica e cultural. As garantias de cidadania e de democracia cultural passam pela elaboração de uma política de sustentação e ampliação do capital cultural. Um plano de cultura municipal deve, necessariamente, ter em conta as garantias da cidadania e da democracia como principais premissas.

O município (o território) é o lugar de maior potencialidade de desenvolvimento cultural. Aqui não estamos falando das artes do espetáculo ou da engenharia do entretenimento, pode-se até chegar a gerar ações que visem a alcançar tais questões. As discussões aqui propostas estão tratando, metaforicamente falando, de alguns passos antes. Estamos nos referindo a um desenvolvimento, como o que propõe o economista Amartya Sen, que considera as "liberdades dos indivíduos os elementos constitutivos básicos" de uma sociedade, e que pensa que as capacidades podem ser tanto expandidas pelas políticas públicas quanto "a direção da política pública pode ser influenciada

8 Adesão ao SNC. http://portalsnc.cultura.gov.br/wp-content/uploads/sites/32/2019/09/2019.09-Quantitativo-atualizado-3.pdf Acesso em: 16/10/2019.. 
pelo uso efetivo das capacidades participativas do povo". (SEN, 2000, p. 32)

Vamos, a partir daqui, apresentar algumas das premissas que consideramos indispensáveis em qualquer processo de construção de planos de cultura municipais, seguidas de alguns princípios norteadores e propostas de ação. A intenção não é a de elaborar um manual, ou um esquema mínimo a ser seguido pela gestão pública e agentes envolvidos na elaboração dos planos de cultura municipais, mas sim, compartiIhar reflexões que foram construídas a partir de processos de observação teórico e prática. Muitas das questões que serão aqui colocadas tendem, em uma conjuntura de amesquinhamento das políticas públicas, para não falar das intolerâncias e dos autoritarismos, a ser desconsideradas por muitos dos que ocupam postos de poder.

A primeira e principal premissa que queremos destacar é a do reconhecimento da importância da cultura para o desenvolvimento do município, do território, do local. Aqui podemos falar dos aspectos do desenvolvimento humano, do desenvolvimento social e do desenvolvimento econômico, assim como do desenvolvimento sustentável. Também no caso das políticas territoriais a ideia de tridimensionalidade, ou "pluridimensionalidade" podem ser acionadas, sempre tendo em vista a transversalidade da cultura no que diz respeito ao conjunto de áreas que compõem o campo das políticas públicas. Imediatamente associada a esta está a premissa da estreita relação entre cultura e qualidade de vida da população, com o reconhecimento, por parte do poder público, das práticas locais nas suas diversidades e complexidades. Também deve estar presente no conjunto das premissas tanto o respeito à memória e às tradições, como também a garantia ao acesso às inovações.
A cultura é um direito fundamental, expresso na Declaração Universal dos Direitos do Homem, no artigo 22, que trata dos direitos econômicos, sociais e culturais, indispensáveis à dignidade e ao desenvolvimento da personalidade. Essa é outra premissa fundamental em todo o processo de elaboração de um plano municipal de cultura. O professor e jurista Allan Rocha de Souza, afirma que:

As justificativas dos direitos cultuais remetem, assim, à formação da pessoa para uma existência digna, à construção das identidades, onde o particular e o social se encontram, à inclusão e o exercício da cidadania cultural, à capacitação para o diálogo intercultural e ao desenvolvimento socialmente sustentável. Todas essas circunstâncias interagem na justificação dos direitos culturais assim como informam seu conteúdo. (SOUZA, 2012, p. 46)

Um plano municipal de cultura deve estar, de alguma maneira, alinhado com o conjunto das políticas públicas elaboradas para o território, sem deixar, é claro, de considerar as especificidades e particularidades de cada uma das áreas. Por determinação constitucional, os governos, em todos os níveis, devem elaborar planos estratégicos plurianuais, eles devem ser de acesso e conhecimento público. Uma das premissas dos planos de cultura também deve ser a de ter as suas ações articuladas com as prioridades estratégicas elencadas pelo governo local. Há, no texto constitucional, uma recomendação de que os planos de cultura também sejam plurianuais. A tendência inicialmente seguida pelos planos, era de que tivessem o prazo de execução de 10 anos, nos moldes do Plano Nacional de Cultura. Essa era uma estratégia que visava a garantir algum nível de continuidade nas políticas. Os planos são monitorados através da efetividade de suas metas no tempo previsto para o cumpri- 
mento das mesmas. De uma maneira geral, a construção das metas estratégicas dos governos municipais costumam respeitar as dinâmicas territoriais, fato que contribui para que, mesmo no caso de um plano de cultura decenal, algumas das questões estratégicas locais sejam consideradas. Um plano municipal tem que refletir as questões locais, tem que demonstrar que os gestores e agentes culturais detém um amplo conhecimento da realidade do território.

A construção de um plano municipal de cultura, em bases democráticas, é uma tarefa que deve ser realizada por representantes do governo e da sociedade civil, deve ser um processo participativo. O reconhecimento da diversidade cultural local, do pluralismo das práticas culturais, dos diversos saberes e fazeres locais, são elementos indispensáveis ainda na fase inicial de um sistema municipal de cultural, seja na elaboração do plano seja na construção do conselho de cultura local. Os elementos que compõem seja o conselho, seja o comitê ou ainda o grupo de trabalha da construção do plano deve, de alguma maneira, espelhar e ter como questão central a diversidade cultural local.

Em um artigo dedicado às questões dos direitos culturais e a cidade, o estudioso Alfons Martinell Sempere, nos apresenta um relato sobre uma experiência concreta, de construção de um documento (uma carta) que deveria servir de referência base para os mais diversos partidos políticos e para os cidadãos. $O$ documento possuía (além do preâmbulo e justificativas) três partes fundamentais: "Os direitos culturais dos cidadãos e cidadãs"; "Os compromissos dos cidadãos e cidadãs"; e, "Os compromissos da administração pública".

Um dos princípios que guia o documento, que nos apresenta Martinell, é o de que as políticas culturais se constroem e se efetivam a partir do diálogo e das ações de responsabilidade tanto do Estado quanto da sociedade. Vamos encontrar, por um lado, recomendações sobre a responsabilidade do Estado de garantir um mínimo de equipamentos de maneira equilibrada pelo território, de ampliar a oferta, de garantir o acesso aos recursos públicos, de fornecer meios de comunicação, entre outras. Mas, por outro lado, também vamos encontrar recomendações para que os proponentes de projetos culturais levem em consideração, em suas propostas, os setores mais vulneráveis da população, a ampliação máxima em termos de diversidade de públicos, a harmonização da expressão cultural proposta com a convivência do espaço público, entre outros. Esse exemplo é muito interessante pois lança luz, de maneira mais efetiva, para o fato de que não é o Estado o responsável direto pela produção e pelo tipo de produto cultural que será apresentado ao público. O que é ofertado, a dinâmica cultural local, deve ser construída com o compromisso com os próprios direitos culturais, em ações de responsabilidade coletiva. Muitos tem direitos e muitos tem deveres, tal ponto não deve ser desconsiderado pelo conjunto dos agentes na construção de um plano municipal.

Existe um largo debate sobre as tensões e contradições entre políticas de regulação social e ações de emancipação social; e sobre a capacidade do Estado em assegurar a multiplicidade de direitos ou criar ações assentadas em conceitos limitadores ou padronizadores das diferenças. Em um artigo $^{9}$ no qual reflete sobre as possibilidades, ou não, do direito ter um papel emancipador na

9 É um artigo que utilizo de maneira recorrente quando trabalho com a temática da participação social. 
sociedade contemporânea e, em especial, na criação de possíveis esferas de representação dos oprimidos e marginalizados, Boaventura Souza Santos propõe que a "sociedade civil insubmissa" deve ter como objetivo:

(...) fomentar sociabilidades da convivialidade entre diferentes identidades culturais sempre que se encontrarem e disputarem um terreno de inclusão e pertença potencialmente comum. Através da sociabilidade, o terreno comum torna-se simultaneamente mais inclusivo e menos comum, ou seja, menos homogeneamente comum a todos os que afirmam pertencer-lhes. (SANTOS, 2003, p. 49)

As reflexões sobre a necessidade da diversidade local estarem presentes no plano, não significa propor uma pasteurização das ações de maneira a criar um todo que não reflete as partes. A problemática das diferentes identidades, como alerta Boaventura, deverá estar expressa no plano, isso também não significa nominar exaustivamente toda a diversidade, mas sim de criar condições para que ela exista, que floresça, sem ser soterrada por um conjunto de ações e regramentos homogeneizadores.

As premissas e princípios acima propostos não são de fácil execução, mas podem ser indicativos do nível de compromisso do governo local com a democracia e a cidadania cultural.

Existem ações, metodologias de gestão, atividades e projetos, que podem tornar mais viável uma política cultural democrática e participativa, tais como: co-gestão de serviços públicos; apoio a museus comunitários; gestão partilhada de equipamentos; fóruns temáticos; realização de escutas públicas; apoio a redes de intercâmbio; implantação de orçamento participativo; entre outros.
Abaixo vamos recuperar duas experiências de impacto territorial, como exemplos de ações que podem estar previstas em planos municipais e que estão diretamente ligadas a questões como: cidadania, identidade, pertencimento e memória.

O apoio à criação de museus comunitários é uma ação destacada no processo de fortalecimento da cidadania cultural e mesmo da cidadania plena. Lugares como museus e centros de memória não devem servir apenas para guardar registros de memória dos grupos dominantes. Temos um exemplo muito interessante da construção de um museu comunitário: o Museu da Maré. No site, o Museu da Maré se apresenta como um:

(...) conjunto de ações voltadas para o registro, preservação e divulgação da história das comunidades da Maré, em seus diversos aspectos, sejam eles culturais, sociais ou econômicos. As ações propostas no Plano Museológico, contemplam o programa institucional, de acervos, de exposição, educativo cultural, de pesquisa e de divulgação da iniciativa. (MUSEU DA MARÉ)

O Museu da Maré foi criado em 2006, no âmbito de uma conjuntura bastante propícia para ações de tal natureza. O Ministério da Cultura estava implementando o Programa Cultura, Educação e Cidadania - Cultura Viva, sendo sua ação de maior repercussão a dos Pontos de Cultura (o Museu da Maré foi um ponto de cultura). Na proposta de criação da instituição, os organizadores do Museu da Maré, deixam muito claro os princípios guia da construção do espaço:

A intenção do Museu da Maré é romper com a tradição de que as experiências a serem rememoradas e os lugares de memória a serem lembra- 
dos são aqueles eleitos pela versão oficial, "vencedora", da história e por isso, uma versão que limita as representações da história e da memória de grandes parcelas da população. Por isso, o Museu da Maré, como uma iniciativa pioneira no cenário da cidade, se propõe a ampliar o conceito museológico, para que este não fique restrito aos grupos sociais mais intelectualizados e a espaços culturais ainda pouco acessíveis à população em geral. A favela é lugar de memória e por isso nada mais significativo do que se fazer uma leitura museográfica a partir de tal percepção. (MUSEU DA MARÉ)

No caso da Maré o trabalho coletivo dos organizadores e da comunidade veio contribuindo para a modificação do conceito de museu, com ênfase no território. O trabalho deu tão certo, que o museu foi várias vezes escolhido para receber exposições em circulação de outras instituições do país, inclusive internacionais. Existe também um trabalho no campo educativo de levar os meninos da comunidade envolvidos com o projeto, para visitar outros museus e trazer jovens de outras localidades para conhecer o Museu da Maré, promovendo uma circulação de ideias e de pessoas. Esse tipo de processo dialoga com questões como a da identidade, do pertencimento, de estar no lugar, cria sentimentos como: "Eu tenho uma identidade!" ou "Eu posso trabalhar a minha identidade!"

Ainda no campo da valorização da memória local há uma interessante experiência realizada no município de Itajaí, no litoral norte do estado de Santa Catarina. A região sul do Brasil foi a de maior concentração de imigração branca europeia no final do século XIX e XX. A área municipal de preservação do patrimônio estava a cargo da Fundação Genésio Miranda Lins, instituída em 1976. O professor e estudioso José Roberto Severino, foi convidado a dirigir a Fundação no período de 2005 a 2008. Ao chegar à nova gestão, foi realizado um diagnóstico inicial, através do qual a equipe registrou o que considerou como uma série de fragilidades institucionais:

A FGML apresentava fraca relação com a memória social nas atividades da instituição; ausência de uma política patrimonial definida; pouca transversalidade com os órgãos governamentais [...]. Notava-se a pouca presença dos indígenas, uma forte presença dos lusos, nenhuma presença dos afrodescendentes e a grande presença dos imigrantes europeus que ancoraram no porto ao longo do século XIX e XX, bem como de todos os descendentes. É flagrante a ausência da memória do agricultor, do pescador, do estivador, do comerciário. (SEVERINO, 2016, p. 101)

Destaca-se que a Fundação possuía um "Conselho de Notáveis" que era formado por especialistas dedicados ao estudo da história oficial da cidade, e que participava da construção da política de guarda da Instituição, inclusive sobre o acervo e a memória a ser preservada. Política essa que gerava as fragilidades acima apontadas no diagnóstico da gestão que assumia.

A partir do diagnóstico, acima citado, foram definidas as diretrizes do trabalho que iria ser desenvolvido para combater as fragilidades encontradas. Como podemos observar havia um processo significativo de exclusão, na preservação da memória social, de uma série de segmentos sociais fundamentais para a construção da história local. Tal comportamento criava, por um lado, sentimentos de não representação e pertencimento em seus descendentes e de outro um baixo grau de identificação 
com os lugares de memória preservados oficialmente. A equipe decidiu estruturar seu trabalho com vistas ao desenvolvimento de políticas de inclusão da diversidade na preservação do patrimônio histórico e cultural da cidade. Segundo Roberto Severino, a escolha metodológica da equipe para aproximação da população, nos mais de 40 bairros do município, foi a participação das reuniões do Orçamento Participativo (OP). Como recorda o gestor, "o estranhamento inicial, logo foi tomado pelo entusiasmo da população em poder decidir, discutir, propor. Tínhamos uma hora por reunião para fazer a apresentação e ouvir dos participantes as demandas relacionadas ao patrimônio" (Idem, p. 101-02). A partir desses primeiros resultados obtidos nas reuniões de discussão do Orçamento Participativo, a equipe da Fundação tomou como tarefa "ouvir a população acerca de uma política patrimonial de inclusão, através das sucessivas entrevistas realizadas para compor um novo acervo, tendo como suporte a história oral" (Idem, p. 102). O desdobramento da ação, foi a criação de uma gerência de Patrimônio Cultura voltada para as minorias e grupos excluídos socialmente.

A gestão do patrimônio cultural no Brasil tem a tradição de concentrar parte significativa de suas ações (ou mesmo a totalidade delas), na preservação do patrimônio edificado, e de estabelecer diálogos quase que exclusivamente com grupos de especialistas que costumam compor os conselhos de área. A forma tradicional de operar com o conceito de patrimônio artístico e histórico, costuma considerar que a preservação deve ter como alvo os estilos arquitetônicos consagrados, ou seja, em geral dos brancos e das elites. Essa forma tradicional de gestão gera um sentimento de exclusão, de ausência de identidade, de parte significativa da população. Esta não se iden- tifica com a memória preservada e representada nos museus e centros culturais.

A experiência da gestão do patrimônio, em Itajaí, promoveu uma apropriação ampliada da memória social local, incluindo na história oficial os elementos, os atores, tradicionalmente ausentes da mesma. Os resultados das entrevistas e das novas documentações que passam a ser incorporadas ao acervo da Fundação, geram uma ampliação das fronteiras da história local. Tais materiais passam a ser matéria de programas da Rádio Universitária local e dos jornais locais, a constar na produção de material didático e de projetos que envolvem os jovens, a memória e a cultura local. Ações de educação patrimonial foram criadas. O projeto foi desdobrado em inúmeras publicações - inclusive com fins didáticos. Enfim, o gestor do projeto avaliou que "dessa forma, as comunidades passaram a ter maior visibilidade e compreensão dos seus saberes e fazeres enquanto patrimônio, buscando estratégias de transmissão desse legado" (Idem, p. 105).

Outras experiências poderiam ser aqui elencadas. O país possui um conjunto de ações desenvolvidas, ainda que pontualmente, que formam um mosaico de experiências que precisam ser estudadas e podem ser replicadas. A autonomia que a Constituição de 1988 deu aos municípios, os permite realizar políticas, planos e ações que extrapolam as ações federais. Existem inúmeras histórias de programas de longo prazo bem sucedidos tais como o Fundo Municipal de Cultura de Porto Alegre ou o Programa de Valorização de Iniciativas Culturais de São Paulo, o VAl.

A elaboração de um plano municipal de cultura tem que levar em conta uma série de desafios que estão postos para a gestão. Nas proposições dos planos e na estruturação das metas a cul- 
tura deve ser pensada, tanto como um processo (contínuo, histórico, enraizado no tecido social) quanto como um produto expresso ora nas múltiplas linguagens (literatura, teatro, música, artes cênicas, artes digitais etc.) ora nos diversos fazeres (brincadeiras, patrimônio imaterial, crenças, práticas de cura etc.). Um plano deve prever ações e mecanismos que garantam o acesso amplo tanto à cultura local como à produção cultural de uma maneira mais ampla, permitindo o fortalecimento e a ampliação dos repertórios locais, sem descuidar da garantia da circulação de informação e diálogos nos mais diferentes níveis de fazeres e saberes.

Existem muitos desafios, muitos (pré)conceitos arraigados que necessitam ser superados tais como o da ideia de que cultura é sinônimo de erudição, que é coisa de artista, que toda produção tem que ter incentivo do estado, ou que é intocável e deve ser protegida das influências externas.

\section{Para concluir}

Vivemos um tempo de contínua descrença ou desrespeito nos pressupostos universalizantes dos direitos, e num país que mantém níveis inconcebíveis e crescentes de desigualdade em pleno século $\mathrm{XXI}$. O campo artístico-cultural está sempre atravessado pela dualidade mercado / estado, colocando a produção cultural sob o risco da lógica da mercadoria. A cultura que é um direito constitucional, logo objeto de políticas públicas, tem ficado subordinada a projetos pouco democráticos e que, em geral, não consideram a diversidade cultural do país. No atual momento a liberdade de expressão dessa diversidade se vê atacada pelo governo federal que reedita práticas de censura, fazendo uso altamente arbitrário dos recursos públicos, rasgando os princípios constitucionais de liberdade de expressão.
Todo esse quadro torna ainda mais fundamental a elaboração de estudos e análises que nos auxiliem a compreender melhor a conjuntura na qual estamos inseridos, os processos históricos que nos trouxeram até aqui, permitindo a construção de novos instrumentos de gestão de políticas públicas, mais inclusivos, transversais, democráticos e participativos.

Em uma conjuntura de crise, como no momento atual, onde assistimos a despolitização das ações cotidianas e a espetacularização da política, o estudioso peruano Víctor Vich chama nossa atenção para o fato de que sempre podemos reinventar novas formas de vida, assim:

El trabajo en cultura es, entonce, un trabajo enfocado y abocado hacia la construcción de una nueva hegemonía: es un trabajo para transformar las normas o habitus que nos constituyen como sujetos, para deslegitimar aquello que se presenta como natural (y sabemos histórico), y para revelar otras posibilidades de individuación y de vida comunitaria, (VICH, 2014, p. 19)

\section{Referências}

BARROS. José Marcio. Diversidade cultural e gestão da cultura. Revista Observatório Itaú Cultural, São Paulo, n. 8, abr.-jul. 2009.

CALABRE, Lia. Estudos Acadêmicos Contemporâneos sobre Políticas Culturais no Brasil: Análises e tendência. PragMATIZES - Revista Latino-Americana de Estudos em Cultura, Niterói, ano 4, n. 7, mar.-set. 2014.

CALABRE, Lia. Políticas Culturais e Participação Social: Visadas históricas e futuros possíveis. In: 
Anais do XIII Encontro de Estudos Multidisciplinares em Cultura. Salvador, 2017.

CALABRE, Lia. Reflexões sobre alguns desafios da gestão pública de cultura no Brasil: participação e organização sistêmica. In: MINC. Seminário Internacional Sistemas de Cultura: Política e gestão cultural descentralizada e participativa. Brasília: MINC; Rio de Janeiro: FCRB, 2016.

CHAUÍ, Marilena. Cidadania cultural: O direito à cultura. São Paulo: Editora Fundação Perseu Abramo, 2006.

CHAUÍ, Marilena. Uma opção radical e moderna: Democracia Cultura. In: Rubim, Albino (org.). Política Cultural e gestão democrática no Brasil. São Paulo: Perseu Abramo, 2017.

GARCIA-CANCLINI, Néstor (ed.). Politicas Culturales en América Latina. México: Editorial Grijalbo, 1987.

MOREIRA, Altair José; FARIA, Hamilton. Cultura e governança: um olhar transversal de futuro para o município. In: FARIA, Hamilton; MOREIRA, Altair José; VERSOLATO, Fernanda. Você quer um bom conselho? Conselhos municipais de cultura e cidadania cultural. São Paulo: Instituto Pólis, 2005.

MUSEU DA MARÉ -. http://www.museudamare.org.br/index.php?option $=$ com_content \&view $=$ article\&id=48\&Itemid $=54$. Acesso em: 20/12/2018.

RUBIM, Antônio Albino Canelas (org.). Políticas culturais no governo Lula. Salvador: EDUFBA, 2010.

RUBIM, Antônio Albino Canelas; BARBALHO, Alexandre (org.). Políticas Culturais no Brasil. Salvador: EDUFBA, 2007.

SAEZ, Guy. Gouvernance culturelle territoriale: les acteurs. In: SAEZ, G. (coord.) Institutions et vie culturelles. Paris: La documentation Française, 2004.

SANTOS, Boaventura Souza. Poderá o direito ser emancipatório? Revista Crítica de Ciências Sociais, n. 65, p. 3-76, maio 2003.

SANTOS, Milton. Da totalidade ao lugar. São Paulo: Edusp, 2005.

SEMPERE, Alfons M. A cidade como espaço privilegiado para os direitos culturais. Revista Ob- servatório Itaú Cultural/OIC, São Paulo, n.11, p. 61-72, jan.-abr. 2011.

SEN, Amartya K. Desenvolvimento como liberdade. São Paulo: Companhia das Letras, 2000.

SEVERINO, José Roberto. Uma experiência de gestão participativa em patrimônio cultural no município de Itajaí - SC. In: RUBIM, Albino (org.). Política Cultural e gestão democrática no Brasil. São Paulo: Ed. Fundação Perseu Abramo, 2016.

SOUZA, Allan Rocha de. Os direitos culturais no Brasil. Rio de Janeiro: Beco do Azougue, 2012.

VICH, Víctor. Desculturalizar la cultura. La gestión cultural como forma de acción política. Buenos Aires: Siglo Vientiuno Editores, 2014. 